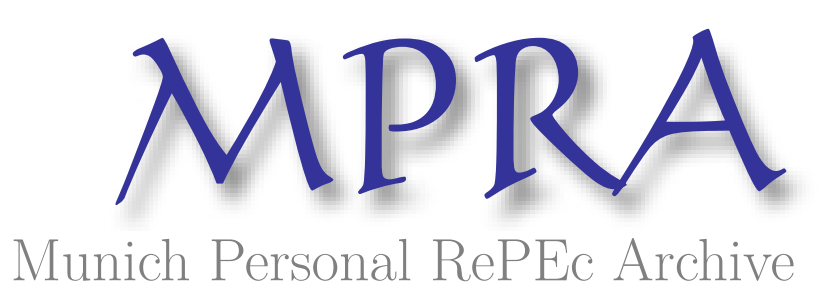

\title{
Inequality and Well-Being
}

Borooah, Vani

University of Ulster

May 2018

Online at https://mpra.ub.uni-muenchen.de/90554/

MPRA Paper No. 90554, posted 16 Dec 2018 03:45 UTC 


\title{
Chapter 7: Inequality and Well-Being
}

\begin{abstract}
In this chapter, Borooah investigates a neglected area in the study of human development relating differences in human development between social groups in a country. Failure to take account of such inter-group inequalities might lead one to exaggerate a country's developmental achievements. Conversely, one would get a more accurate picture of a country's achievements with respect to human development only after one had taken cognisance of the fact that the fruits of development were unequally distributed between its various communities. There is a further issue. Not only are developmental fruits unequally distributed between groups, but these fruits may be unequally distributed within the groups. In this chapter, Borooah uses the methodology of "equity adjusted achievement" to compute human development indices and "extended" human development indices for a number of social groups in India.
\end{abstract}

\subsection{Introduction}

The Organisation for Economic Co-operation and Development (OECD) recently observed that "Concerns have emerged regarding the fact that macro-economic statistics did not portray the right image of what ordinary people perceived about the state of their lives. Addressing these concerns is crucial, not just for the credibility and accountability of public services, but for the very functioning of our democracies" (OECD, 2011, p. 4). Other economists and non-economists have expressed concern that by identifying welfare exclusively in terms of money income, public policy has lost its way. As a consequence, there has been — and still is - an undue concentration of both public and private resources on raising national income: "undue", because making people richer does not necessarily improve their well-being or, at any rate, not by enough to justify the outlay of resources in raising income. In other words, public policy, with its focus on raising national income, may not be giving people what they want; for this reason, there is a growing restlessness among social scientists about the wisdom of harnessing economic policy to the yoke of economic performance (Frank, 1997, 1999; Layard, 2006). 
The United Nations, too, recognises that income is not an end in itself but rather a means to achieving the much broader goal of "human development" and that, towards achieving this goal, noneconomic factors — such as levels of crime, the position of women, respect for human rights etc. may, in addition to income, make an important contribution. In order to breathe life into this perspective, the UNDP regularly publishes, as part of its annual Human Development Report, a ranking of over 100 countries in terms of their values on the Human Development Index (HDI). This index, while having GDP performance as one of its components, also takes into account countries' "achievements" with regard to educational (for example, literacy rates) and health-related (for example, life expectancy) outcomes. "Well-being", so conceived, may be related to poverty but it is also quite distinct from it (Subramanian, 2004).

The term "human development" is widely used by the media, politicians, NGOs, and governments all over the world to mean the capacity of people to fulfil their potential in all the domains in which they function — inter alia health, education, and income. This concept of development - based on an expansion of capabilities to function in life, in all its variety and richness — is arguably a more productive and more expressive view than one based solely on economic growth. This is a concept which owes much to the work of, among others, Anand and Sen (1994, 1997, 2003), Haq (1994), and Sen (1992). The computation of the Human Development Index, and the ranking of countries on the basis of their HDI values, have become are regular features of public debate since the HDI was first published by the United Nations Development Programme (UNDP, 1995, 2000). Another regular feature of HDI is its calculation on a national (and indeed, sub-national basis), in which different regions of a country are ranked on the basis of their human development (for example, Shariff, 1999).

Anand and Sen (1994), in a paper prepared for the 1995 Human Development Report, pointed out that a country's non-economic achievements were likely to be unequally distributed between subgroups of its population. For example, in terms of gender equality — which was the focus of their

\footnotetext{
${ }^{1}$ The rankings of the various countries in terms of their per-capita GDP and their HDI index can often be very different. If one defines $X$ as the difference between a country's GDP rank and its HDI rank, then as UNDP (2000) shows, $X$ is significantly non-zero for several countries. For example, $X=13$ for the UK (implying that the UK's HDI ranking was 13 places higher than its GDP ranking) while $X=-16$ for Luxembourg (implying that Luxembourg's HDI ranking was 16 places lower than its GDP ranking).
} 
concern - the female literacy rate, or female life expectancy, were often lower than for males. In the face of such inter-group inequality, they argued that a country's achievement with respect to a particular outcome should not be judged exclusively by its mean level of achievement (for example, by the average literacy rate for a country) but rather by the mean level adjusted to take account of inter-group differences in achievements. They proposed a method, based on Atkinson's (1970) seminal work on the relation between social welfare and inequality, for making such adjustments: they termed the resulting indicators equity sensitive indicators. This would then allow a comparison between two countries, one of which had a lower mean achievement level, but a more equitable distribution of achievement, than the other. They further suggested that assessments of country achievements should be made on the basis of such equity sensitive indicators rather than, as was often the case, on the basis of its mean level of achievement. ${ }^{2}$

A neglected area in the study of human development has been differences in human development between social groups in a country. So, for example, one might know the value of the HDI for India in its entirety but fail to adjust this value for the fact that India's achievements with respect to the components of the HDI may be unequally distributed between its various social groups: a national literacy rate may co-exist with high rates of literacy for upper caste Hindus and low rates for the Scheduled Castes and Scheduled Tribes. Failure to take account of such inter-group inequalities might lead one to exaggerate India's developmental achievements. Conversely, one would get a more accurate picture of India's achievements with respect to human development only after one had taken cognisance of the fact that the fruits of development were unequally distributed between its various communities.

There is, however, a further issue. Not only are developmental fruits unequally distributed between groups — in the sense that, as observed above, inter-group average incomes may differ but these fruits may be unequally distributed within the groups. The former type of inequality is the domain of inter-group inequality and the latter type of inequality is the domain of within-group

\footnotetext{
${ }^{2}$ Anand and Sen (1997) compared Honduras (with an average literacy rate of $75 \%$, distributed between men and women as $78 \%, 73 \%$ ) with China (with an average literacy rate of $80 \%$, distributed between men and women as $92 \%, 68 \%$ ) and asked which country should be regarded as having the "better" achievement with regard to literacy: China with a higher overall rate or Honduras with greater gender equality?
} 
inequality with overall inequality being a composite of between- and within-group inequality. So, pursuing the Anand and Sen $(1994,1997)$ argument to its logical conclusion, a "proper" assessment of a country's achievement with respect to an indicator requires us to take account of inequality not just in the distribution of that achievement between its social groups but also, within each group, inequality in the distribution of that achievement between the group's members. ${ }^{3}$

The details of the methodology, expressed in mathematical form, which underpins this concept of "equity-adjusted achievement", are contained in the following two sections. Then, in subsequent sections, we use this methodology to compute human development indices and "extended" human development indices for a number of social groups in India. As is well known, conventional human development indices embody three elements: education (literacy rate); health (life expectancy); and income. To this list, we added two further components to arrive at an 'extended' HDI: living conditions and social networks. Living conditions are important because many households in India lack, for example, even basic toilet facilities or ventilation in their cooking area. Social networks are important because there is a great volume of, admittedly anecdotal, evidence from India to suggest that it is difficult, if not impossible, to access essential services easily unless one has personal contacts or, in the vernacular, has jaan-pehchaan.

The results reported in this chapter are based on data from the India Human Development Survey which relates to the period 2011-12 (hereafter, IHDS-2011). ${ }^{4}$ This is a nationally representative, multi-topic panel survey of 42,152 households in 384 districts, 1420 villages and 1042 urban neighbourhoods across India. Each household in the IHDS-2011 was the subject of two hourlong interviews. These interviews covered inter alia issues of: health, education, employment, economic status, marriage, fertility, gender relations, and social capital. The IHDS-2011, like its predecessors for 2005 and 1994, was designed to complement existing Indian surveys by bringing together a wide range of topics in a single survey. This breadth permits the analysis of associations across a range of social and economic conditions.

\footnotetext{
${ }^{3}$ These "members" could be households or persons.

${ }^{4}$ Desai et al. (2015).
} 


\subsection{Equity Sensitive Achievements}

Suppose that there are $\mathrm{N}$ households in a country (with measured achievements, $X_{1}, X_{2}, \ldots, X_{N}$ ), which can be separated into $K$ mutually exclusive social groups ( $k=1 \ldots K$ ) with $N_{k}$ households ( $\left.i=1 \ldots N_{k}\right)$ in each group, each household with an achievement, $X_{i k}, i=1 \ldots N_{k}, k=1 \ldots K$. We know that the average achievement of a country is not achieved by all its groups. Similarly, the average achievement of a group is not achieved by all its members. In other words, there is inequality in the distribution of achievements between groups and between individuals in groups. If, as is the convention in economics, we regard inequality as undesirable (a "bad") then, in assessing the achievement of a country or of a group, by how much should we reduce its average achievement to take account of inequality in achievements?

The answer to this question depends on how averse we are to inequality. In his seminal paper on income inequality, Atkinson (1970) argued that we (society) would be prepared to accept a reduction from a higher average income which was unequally distributed to a lower average income which was equally distributed. ${ }^{5}$ The size of this reduction would depend upon our degree of "inequality aversion", which Atkinson (1970) measured by the value of an "inequality aversion parameter", $\varepsilon \geq 0$. When $\varepsilon=0$, we are not at all averse to inequality implying that we would not be prepared to accept even the smallest reduction in average income in order to secure an equitable distribution. The degree of inequality aversion increases with the value of $\varepsilon$ : the higher the value of $\varepsilon$, the more averse we are to inequality and the greater the reduction in average income we would find acceptable to secure an equal distribution of income.

These ideas can equally well be applied to the measurement of non-income achievements. We can reduce the average achievement, $\bar{X}=\sum_{i=1}^{N} X_{i}$, of a country by the amount of inter-group inequality in achievements to arrive at $X^{e}$, a "group-equity sensitive" achievement for the country: $X^{e} \leq \bar{X}$. Similarly, we can reduce the average achievement, $\bar{X}_{k}$, of a group by the amount of intra-

\footnotetext{
${ }^{5}$ In the language of economics, the two situations would yield the same level of social welfare, i.e. be "welfare equivalent".
} 
group inequality in achievements to arrive at $X_{k}^{e}$, a "person-equity sensitive" achievement for the group: $X_{k}^{e} \leq \bar{X}_{k}$. We refer to $X^{e}$ and $X_{k}^{e}$ as equally distributed equivalent achievements: $X^{e}$, when it is the achievement of each of the groups (that is, equally distributed between the groups), is welfare equivalent to $\bar{X}$; and $X_{k}^{e}$, when it is the achievement of every member of group $k$ (that is, equally distributed between individuals in a group), is welfare equivalent to $\bar{X}_{k}$. The size of these reductions (as given by the differences: $\bar{X}-X^{e}$ and $\bar{X}_{k}-X_{k}^{e}$ ) depends upon our aversion to inequality: the lower our aversion to inequality, the smaller will be the difference; in the extreme case in which there is no aversion to inequality, there will be no difference between the average, and the equity sensitive, achievements.

Three special cases, contingent upon the value assumed by $\varepsilon$, the inequality aversion parameter, can be distinguished:

1. $\varepsilon=0$ (no inequality aversion), $X^{e}$ and $X_{k}^{e}$ are the arithmetic means of, respectively, the group achievements and of the achievements of persons in group $k: X^{e}=\bar{X}$ and $X_{k}^{e}=\bar{X}_{k}$

2. $\varepsilon=1, X^{e}$ and $X_{k}^{e}$ are the geometric means of, respectively, the group achievements and of the achievements of persons in group $k: X^{e}=\left[\prod_{k=1}^{K}\left(X_{k}\right)^{N_{k}}\right]^{1 / K}<\bar{X}$ and $X_{k}^{e}=\left[\prod_{i=1}^{N_{k}} X_{i k}\right]^{1 / N_{k}}<\bar{X}_{k}$.

3. $\varepsilon=2, X^{e}$ and $X_{k}^{e}$ are the harmonic means of, respectively, the group achievements and of achievements of persons in group $k: X^{e}=\left[\sum_{k=1}^{K} \frac{n_{k}}{X_{k}}\right]^{-1}<\bar{X}$ and $X_{k}^{e}=\left[\frac{1}{N_{k}} \sum_{i=1}^{N_{k}} \frac{1}{X_{i k}}\right]^{-1}<\bar{X}_{k}$

\section{A Diagrammatic Analysis}

It may be useful to present the analysis of the preceding paragraphs in diagrammatic terms. Figure 7.1 portrays a world of two persons ( $R$ and $S$ ) who are required to "share" an achievement, say a given mean wage, $W$, in terms of their individual wages, $W_{R}$ and $W_{S}$. The horizontal axis of Figure 7.1 
measures $W_{R}$ and the vertical axis measures $W_{S}$. The two wages are related to the aggregate wage by the "sharing" equation: $W=\left(W_{R}+W_{S}\right) / 2$ and this is represented in Figure 7.1 by the "sharing possibility line", $M N$. The point $X$, on $M N$, lies on the $45^{0}$ line passing through the origin and, so, $X$ is the point at which $W_{R}=W_{S}$.

$<$ Figure 7.1>

Given the mean wage, $W$, the observed distributional outcome may be viewed as a mapping of $W$ to a point on MN which establishes $W_{R}$ and $W_{S}$. Different outcomes will locate at different points of MN. Those that locate closer to the point $X$ (for example, $B$ ) will be more egalitarian than those (like $A$ ) which locate further away.

If every person is assigned the same concave utility function $U($.$) , then U\left(W_{i}\right)$ is the utility that person $i(i=R, S)$ obtains from a wage of $W_{i}$ and 'social welfare', denoted by $Q$, is defined as the sum of the utilities of all the children:

$$
Q=U\left(W_{R}\right)+U\left(W_{S}\right)
$$

The curves QQ and $\mathrm{Q}^{\prime} \mathrm{Q}^{\prime}$ represent indifference curves associated with the welfare function of equation (7.1), the higher curve (QQ) representing a higher level of utility than the lower curve ( $\mathrm{Q}^{\prime}$ $\left.\mathrm{Q}^{\prime}\right)$ and these welfare indifference curves are superimposed upon the sharing possibility line. ${ }^{6}$ Since the utility functions $U($.$) in equation (7.1) are assumed to be concave (that is, embodying the property$ of diminishing marginal utility), social welfare is maximised when $W_{R}=W_{S}$ that is, when both receive the same wage. ${ }^{7}$ Consequently, $X$ is the point at which welfare is maximised and is the point at which the indifference curve, $Q Q$, is tangential to the sharing possibility line, $M N$. The distribution, however, delivers an outcome at point $A$ at which person $R$ receives a higher wage $\left(W_{R}=O F\right)$ and person $S$ a lower score $\left(W_{S}=A F\right)$. The outcome at point $A$ is welfare equivalent to that at point $C$ at

\footnotetext{
${ }^{6}$ An indifference curve shows the different combinations of $W_{R}, W_{S}$ which yield the same level of welfare. It is obtained by holding $Q$ constant in equation (7.1) and solving for the different $W_{R}, W_{S}$ which yield this value of $Q$. ${ }^{7}$ Because of concavity, an egalitarian transfer from $R$ to $S$ will increase welfare: the gain in utility to $S$ will exceed the loss to $R$. Welfare will be maximised when no further net gain is possible, that is, when $W_{R}=W_{S}$.
} 
which both persons receive the same score $\left(W_{R}=W_{S}=C D\right)$. $C D$ is then defined as the equally distributed equivalent (ede) wage.

$<$ Figure 7.2>

The value of the inequality aversion parameter, $\varepsilon$ determines the curvature of the indifference curves. The larger the value of $\varepsilon$, the more 'bow-shaped' will be the indifference curve and the smaller the value of $\varepsilon$, the flatter will be the indifference curve. This is illustrated in Figure 7.2 in which $Q Q$ and $W W^{\prime}$ represent, respectively, indifference curves associated with low and high values of $\varepsilon$. Both curves pass through the point $A$ on the sharing possibility line $M N$ but $C D$, the equity sensitive score associated with $Q Q\left(\right.$ low $\varepsilon$ ), is greater than $\mathrm{C}^{\prime} \mathrm{D}^{\prime}$, the ede score associated with $Q^{\prime} Q^{\prime}$ (high $\varepsilon$ ).

\subsection{A Formal Analysis of Equity-Sensitive Indicators}

More formally, social welfare, $W$, is defined as the sum of the concave group utility functions $F\left(\bar{X}_{k}\right)$ so that:

$$
W=\sum_{k=1}^{K} N_{k} F\left(\bar{X}_{k}\right)
$$

The change in welfare following a change in the $\bar{X}_{k}$ is:

$$
\Delta W=\sum_{k=1}^{K} a_{k} N_{k} \Delta X_{k}
$$

Where: $a_{k}=\frac{\partial F\left(\bar{X}_{k}\right)}{\partial \bar{X}_{k}}>0$, is the marginal change in social welfare consequent upon changes in group achievements $\left(\Delta X_{k}\right)$ and also termed the "welfare weight" associated with group $k$. Since it is assumed that the functions $F($.$) are strictly concave, marginal gain decreases with increasing$ achievements: consequently, social welfare is maximised when achievements are equal across groups $: \bar{X}_{1}=\bar{X}_{2}=\ldots=\bar{X}_{K}$.

The social welfare function, $W$, in equation (7.2) has constant elasticity if, for $\varepsilon>0, F($.$) can be$ written as: 


$$
F\left(\bar{X}_{k}\right)=\frac{\bar{X}_{k}^{1-\varepsilon}-1}{1-\varepsilon}, \varepsilon \neq 1, \varepsilon>0 ; F\left(\bar{X}_{k}\right)=\alpha+\beta \log \left(\bar{X}_{k}\right), \varepsilon=1
$$

since then: $a_{k}=\frac{\partial F\left(\bar{X}_{k}\right)}{\partial \bar{X}_{k}}=\left(\bar{X}_{k}\right)^{1-\varepsilon} \Rightarrow \frac{\partial a_{k}}{\partial \bar{X}_{k}} \frac{\bar{X}_{k}}{a_{k}}=-\varepsilon \bar{X}^{-(1+\varepsilon)} \frac{\bar{X}_{k}}{\bar{X}_{k}^{-\varepsilon}}=-\varepsilon$. Consequently, the percentage change in the welfare weight, $a_{k}$, associated with group $k$, following an increase in its achievement, $\bar{X}_{k}$, is constant and negative. The larger the value of the parameter $\varepsilon>0$, the greater will be the fall in the welfare weight.

Similarly, the social welfare of a group $W_{k}, k=1 \ldots K$ is defined as the sum of the concave utility functions of the group's members, $F\left(\bar{X}_{k}\right)$ so that:

$$
W_{k}=\sum_{i=1}^{N_{k}} F\left(X_{i k}\right)
$$

Implying: $\Delta W_{k}=\sum_{i=1}^{N_{K}} a_{i k} \Delta X_{i k}$ where the welfare weights, $a_{i k}$ are defined as: $a_{i k}=\frac{\partial F\left(X_{i k}\right)}{\partial X_{i k}}>0$.

The social welfare function, $W_{k}$, in equation (7.4) has constant elasticity if, for $\varepsilon>0, F($.$) can$ be written as:

$$
F\left(X_{i k}\right)=\frac{X_{i k}^{1-\varepsilon}-1}{1-\varepsilon}, \varepsilon \neq 1, \varepsilon>0 ; F\left(X_{i k}\right)=\alpha+\beta \log \left(X_{i k}\right), \varepsilon=1
$$

Since $X^{e}$ is welfare equivalent to $\bar{X}$ and since $X_{k}^{e}$ is welfare equivalent to $\bar{X}_{k}^{e}$ we have Atkinson's inequality index, $I$, derived as ${ }^{8}$ :

$$
I=1-\left(\frac{X^{e}}{\bar{X}}\right)=1-\left[\sum_{k=1}^{K} n_{k}\left(\frac{\bar{X}_{k}}{\bar{X}}\right)^{1-\varepsilon}\right]^{1 / 1-\varepsilon} \text { and } I_{k}=1-\left(\frac{X_{k}^{e}}{\bar{X}_{k}}\right)=1-\left[\frac{1}{N_{k}} \sum_{i=1}^{N_{k}}\left(\frac{X_{i k}}{\bar{X}_{k}}\right)^{1-\varepsilon}\right]^{1 / 1-\varepsilon}
$$

where, in equation (7.7), $I$ represents the overall index and $I_{k}$ represents the inequality index for group $k$.

From equation (7.7):

$$
\begin{aligned}
& { }^{8} \text { Since, by welfare equivalence of } X^{e} \text { and } \bar{X} \\
& N F\left(X^{e}\right)=\sum_{k=1}^{K} N_{k} F\left(X_{k}\right) \Rightarrow\left(X^{e}\right)^{1-\varepsilon}-1=\sum_{k=1}^{K} n_{k}\left(X_{k}^{1-\varepsilon}-1\right) \Rightarrow\left(X^{e}\right)^{1-\varepsilon}=\sum_{k=1}^{K} n_{k} X_{k}^{1-\varepsilon} \text {. Dividing both sides by } \bar{X}^{1-\varepsilon}, \\
& \left(\frac{X^{e}}{\bar{X}}\right)^{1-\varepsilon}=\sum_{k=1}^{K} n_{k}\left(\frac{X_{k}}{\bar{X}}\right)^{1-\varepsilon} \Rightarrow 1-\left(\frac{X^{e}}{\bar{X}}\right)=1-\left[\sum_{k=1}^{K} n_{k}\left(\frac{X_{k}}{\bar{X}}\right)^{1-\varepsilon}\right]^{1 / 1-\varepsilon}
\end{aligned}
$$




$$
\left(X^{e}\right)^{1-\varepsilon}=\sum_{k=1}^{N_{k}} n_{k}\left(\bar{X}_{k}\right)^{1-\varepsilon} \text { and }\left(X_{k}^{e}\right)^{1-\varepsilon}=\sum_{i=1}^{N_{k}} \frac{1}{N_{k}} X_{i k}^{1-\varepsilon}
$$

From equation (7.8):

$$
\begin{aligned}
& \left(X^{e}\right)^{1-\varepsilon}=\sum_{i=1}^{N} \frac{1}{N}\left(X_{i k}\right)^{1-\varepsilon} \\
& =\frac{N_{1}}{N} \sum_{i=1}^{N_{1}} \frac{1}{N_{1}}\left(X_{i 1}\right)^{1-\varepsilon}+\frac{N_{2}}{N} \sum_{i=1}^{N_{2}} \frac{1}{N_{2}}\left(X_{i 2}\right)^{1-\varepsilon}+. .+\frac{N_{K}}{N} \sum_{i=1}^{N_{K}} \frac{1}{N_{K}}\left(X_{i K}\right)^{1-\varepsilon} \\
& =n_{1}\left(X_{1}^{e}\right)^{1-\varepsilon}+n_{2}\left(X_{2}^{e}\right)^{1-\varepsilon}+\ldots+n_{K}\left(X_{K}^{e}\right)^{1-\varepsilon}=\sum_{k=1}^{K} n_{k}\left(X_{k}^{e}\right)^{1-\varepsilon}
\end{aligned}
$$

Equation (7.9) represents what Anand and Sen (1994) refer to as “(1-E) averaging)": the overall equally distributed equivalent achievement, $X^{e}$ is a weighted average, with exponent $1-\varepsilon$, of the group equally distributed equivalent achievements, $X_{k}^{e}(k=1 \ldots K)$.

A special case occurs when $\varepsilon=0$ (no inequality aversion). In that situation, $X^{e}$ and $X_{k}^{e}$ are the arithmetic means of, respectively, the group achievements and of the achievements of persons in group $k: X^{e}=\bar{X}$ and $X_{k}^{e}=\bar{X}_{k}$. When $\varepsilon>0$ (there is positive inequality aversion), $X^{e}<\bar{X}$ and $X_{k}^{e}<\bar{X}_{k}$

\section{The Welfare Effects of Redistribution}

To examine the welfare effects of an inter-group redistribution of achievements, consider two social groups - Hindus $(k=C)$ and Muslims $(k=D)$ - and suppose that, within the context of a fixed overall achievement $\bar{X}$, there is a redistribution of achievements (say, income) from Hindus towards Muslims. Then this implies that

$$
\Delta \bar{X}=n_{C} \Delta \bar{X}_{C}+n_{D} \Delta \bar{X}_{D}=0 \Rightarrow-\Delta \bar{X}_{C}=\left(n_{C} / n_{D}\right) \bar{X}_{D}=\theta \Delta \bar{X}_{D} \text {, where }: \Delta \bar{X}_{C}<0, \Delta \bar{X}_{D}>0
$$

The change in social welfare that results from this redistribution is:

$$
\begin{aligned}
& \Delta W=\frac{\partial F\left(\bar{X}_{C}\right)}{\partial \bar{X}_{C}} N_{C} \Delta \bar{X}_{C}+\frac{\partial F\left(\bar{X}_{D}\right)}{\partial \bar{X}_{D}} N_{D} \Delta \bar{X}_{D}=a_{C} N_{C} \Delta \bar{X}_{C}+a_{D} N_{D} \Delta \bar{X}_{D} \\
& =\bar{X}_{C}^{-\varepsilon} N_{C} \Delta \bar{X}_{C}+\bar{X}_{D}^{-\varepsilon} N_{D} \Delta \bar{X}_{D}
\end{aligned}
$$

Setting $\Delta W=0$ in equation (7.10) yields: 


$$
\left(\frac{\bar{X}_{C}}{\bar{X}_{D}}\right)^{-\varepsilon}\left(\frac{N_{C}}{N_{D}}\right) \Delta \bar{X}_{C}=\Delta \bar{X}_{D} \Rightarrow \Delta \bar{X}_{C}=\lambda^{\varepsilon} \theta \Delta \bar{X}_{D}
$$

where: $\lambda=\frac{\bar{X}_{C}}{\bar{X}_{D}}>1$ and $\theta=\frac{N_{D}}{N_{C}}$.

Suppose that through appropriate redistribution policies, the achievement (income) of Muslims is increased by one unit. If $\varepsilon=0$, from equation (7.11), in order to keep the overall achievement, $\bar{X}$, unchanged, the achievement (income) of Hindus must fall by $\Delta \bar{X}_{C}=\theta$. If the fall in the achievement of Hindus exceeded $\theta$, then that would lower the overall achievement $\bar{X}$ and, therefore, overall welfare, $W$.

Since, if $\varepsilon>0 \Delta \bar{X}_{C}=\lambda^{\varepsilon} \theta>\theta$, the achievement of upper-caste Hindus can fall by more than $\theta$ - the amount required to keep $\bar{X}$ unchanged — and still keep welfare unchanged. In other words, for $\varepsilon>0$, society would be prepared to tolerate a fall in the overall achievement $(\Delta \bar{X}<0)$ in order to redistribute from Hindus to Muslims, leaving overall welfare unchanged. The greater the value of $\varepsilon$, the greater will be this tolerance.

\subsection{The Equity --Sensitive Human Development Index: Theory}

Given a list of $M$ achievement indicators (indexed, $j=1 \ldots M$ ) — hereafter referred to as, simply, "indicators" - a country's performance index (PI) with respect to indicator $j, A_{j}$, is defined as

$$
A_{j}=\frac{X_{j}-\operatorname{Min}\left\{X_{j}\right\}}{\operatorname{Max}\left\{X_{j}\right\}-\operatorname{Min}\left\{X_{j}\right\}} \times 100
$$

Where $A_{j}$ is the PI of a country in respect of achievement $j(j=1,2, \ldots, M), X_{j}$ is the value of indicator $j$ and $\operatorname{Max}\left\{X_{j}\right\}$ and $\operatorname{Min}\left\{X_{j}\right\}$ are, respectively, the maximum and minimum values of the indicator.

Equation (7.13) implies that $0 \leq A_{j} \leq 100, j=1 \ldots M$ so that $A_{j}$ represents the percentage performance of the country with respect to the $j^{\text {th }}$ indicator. The overall performance of the country is then the value of its Human Development Index (HDI) and this is defined as the average of the $M$ performance indices: 


$$
H D I=\frac{1}{M} \sum_{j=1}^{M} A_{j}
$$

This section applies the idea of the HDI to a situation where the population of a country is subdivided into $K$ mutually exclusive groups indexed $k=1 \ldots K$. For every household in each group, we compute the value of its PI in respect of $M$ indicators where these are represented by $A_{j k h}, j=1 \ldots M ; k=1 \ldots . . K$; and $h=1 \ldots H_{k}$, where $H_{k}$ is the number of households in group $k$. So, for any group $k(k=1 \ldots K)$ and indicator $j(j=1 \ldots M)$, the components of the vector $\mathbf{A}_{\mathbf{j k}}=\left(A_{j k 1}, A_{j k 2}, \ldots A_{j k H_{k}}\right)$ represents the distribution of the PI with respect to indicator $j$ over the $H_{k}$ households in group $k$. We can then define by $A_{j k}^{e}$ the equally distributed equivalent performance index, or EDEPI, of group $k$ with respect to indicator $j$ as the (1-E) average — as defined in equation (7.9) — of the PI of the groups' households:

$$
\left(A_{j k}^{e}\right)^{1-\varepsilon}=\frac{1}{H_{k}} \sum_{h=1}^{H_{k}}\left(A_{j k h}\right)^{1-\varepsilon}
$$

When $\varepsilon=0, A_{j k}^{e}$ is the arithmetic mean of the household PI; when $\varepsilon>0, A_{j k}^{e}$ is less than the arithmetic mean of the households' PI.

The overall EDEPI for group $k, k=1 \ldots K$ is:

$$
A_{k}^{e}=\frac{1}{M} A_{1 k}^{e}+\frac{1}{M} A_{2 k}^{e}+\ldots+\frac{1}{M} A_{M k}^{e}
$$

The EDEPI aggregated over all the households in all the groups, with respect to attainment $j$, and taking account of both within and between group inequalities, is denoted $A_{j}^{e}$ where:

$$
\left(A_{j}^{e}\right)^{1-\varepsilon}=\frac{1}{H} \sum_{k=1}^{K} \sum_{h=1}^{H_{k}}\left(A_{j k h}^{e}\right)^{1-\varepsilon}
$$

where: $H=\sum_{k=1}^{K} H_{k}$ is the total number of households in the country.

The overall EDE performance index over all the groups, taking account of both inter-and intra-group inequality is: 


$$
A^{e}=\frac{1}{M}\left(A_{1}^{e}+A_{2}^{e}+\ldots+A_{M}^{e}\right)
$$

\section{The Decomposition of the Human Development Index}

Setting $\varepsilon=0$ in equation (7.17) and using equation (7.15) yields:

$$
A_{i}^{e}=\frac{1}{H} \sum_{k=1}^{K} \sum_{h=1}^{H_{k}} A_{i k h}^{e}=\frac{1}{H} \sum_{k=1}^{K} \frac{H_{k}}{H_{k}} \sum_{h=}^{H_{k}} A_{i k h}^{e}=\sum_{k=1}^{k} \frac{H_{k}}{H} \frac{1}{H_{k}} \sum_{h=1}^{H_{k}} A_{i k h}^{e}=\sum_{k=1}^{k} \frac{H_{k}}{H} A_{i k}^{e}
$$

If within-group inequalities are ignored then, in each group, every household is assumed to have the mean PI of that group: $A_{j h k}=\bar{A}_{j k}, h=1 \ldots H_{k}$, (for $i=1 \ldots M$ and $\left.k=1, \ldots K\right)$. The only inequality is between group inequality resulting from the fact that the mean PI of the groups, with respect to indicator $j$, are different: $\bar{A}_{j 1} \neq \bar{A}_{j 2} \neq \ldots \neq \neq \bar{A}_{j K}$ The equally distributed equivalent performance indicator (EDEPI), aggregated over all the groups, with respect to attainment $i$, taking account of between group inequalities only, is denoted $B_{j}^{e}$ where:

$$
\left(B_{j}^{e}\right)^{1-\varepsilon}=\sum_{k=1}^{K} n_{k}\left(\bar{A}_{j k}\right)^{1-\varepsilon}
$$

where: $n_{k}$ is the proportion of households in group $k, k=1 . . K$. Then:

The overall EDEPI over all the households in all groups, taking account of only inter-group inequality is:

$$
B^{e}=\frac{1}{M} \sum_{j=1}^{M} B_{j}^{e}
$$

When $\varepsilon=0$, so that there is no aversion to between-group inequality, $B_{j}^{e}=\bar{B}_{j}$ where $\bar{B}_{j}=\sum_{k=1}^{K} n_{k} A_{j k}$ is the mean of the PI of the indicator $\mathrm{j}$ computed over households in all the groups. In this case, equation (7.21) becomes:

$$
\bar{B}=\frac{1}{M} \sum_{j=1}^{M} \bar{B}_{j}
$$


which is, in fact, the HDI defined in equation (7.14). The $\bar{B}$ in equation (7.22) or, equivalently, the HDI in equation (7.14) is a special case of $A^{e}$ in equation (7.18) and obtains when both inter- and intra-group inequality in the distribution of the PI between the households in the country is ignored.

\subsection{The Human Development Index: Practicalities}

In practical terms, the Human Development Index (HDI) has been formulated in terms of a country's shortfall in respect of three "dimensions": living standards, education, and health. Suppose that $X, Y$, and $Z$ are the values of a country's performance indices with respect to each of these three dimensions and suppose that $\operatorname{Max}(X), \operatorname{Max}(Y)$, and $\operatorname{Max}(Z)$ are the maximum — and $\operatorname{Min}(X), \operatorname{Min}(Y)$, and $\operatorname{Min}(Z)$ are the minimum — values of these achievements. For example, per-capita gross domestic product (GDP) is used as a surrogate for living standards with the assumption, say, that $\operatorname{Max}(X)=\$ 40,000$ and $\operatorname{Min}(Z)=\$ 100$; if $Y$, the literacy rate in a country, is used as a surrogate for the education dimension then $\operatorname{Max}(Y)=100$ and $\operatorname{Min}(Y)=0$; if $Z$, the life expectancy at birth is used as a surrogate for the health dimension then (it is assumed) $\operatorname{Max}(Z)=85$ and $\operatorname{Min}(Z)=25$.

Following from this, the index for each achievement is defined as:

$$
\text { Performance Index }=\frac{\text { Observed value }- \text { Minimum value }}{\text { Maximum value }- \text { Minimum value }} \times 100
$$

and the HDI is defined as:

$$
H D I=\frac{\text { Index }^{x}+\operatorname{Index} x^{Y}+\text { Index }^{z}}{3}
$$

Now suppose that there are two groups. If we consider the performance index (PI) with respect to income, ${ }^{9}$ households within each group will have different PI values and this will yield the group's average PI value: suppose $\bar{X}_{1}$ represents group 1's average PI value and $\bar{X}_{2}$ represents group 2's average PI value. ${ }^{10}$ The PI value for each group represents the average distance between its actual income and its potential income: so, for example, $\mathrm{PI}=65$ for a group means that, on average, it fulfils $65 \%$ of its income potential.

One can compute, for each group, its equally distributed equivalent performance index (EDEPI) with respect to income by taking account of income inequality between the households in the

\footnotetext{
${ }^{9}$ That is, Index $x_{\text {income }}=\frac{\text { Observed Income }- \text { Minimum Income }}{\text { Maximum Income }- \text { Minimum Income }}$

${ }^{10}$ Unless explicitly stated otherwise, the average will always be taken to be the arithmetic mean.
} 
groups: these are denoted $X_{1}^{e}$ and $X_{2}^{e}$. By definition: $X_{1}^{e} \leq \bar{X}_{1}$ and $X_{2}^{e} \leq \bar{X}_{2}$ with equality holding if, and only if, there was no aversion to inequality $(\varepsilon=0)$ in computing the EDEPI for income. As shown in the previous section, the $X_{1}^{e}$ and $X_{2}^{e}$ are calculated through a process of " $(1-\varepsilon)$ averaging", described in equations (6.9) and (6.15). In addition to computing $X^{e}$, we can also compute the EDEPI for education (the literacy rate) for groups 1 and 2 as, $Y_{1}^{e}$ and $Y_{2}^{e}$ and the EDEPI for health (life expectancy) as $Z_{1}^{e}$ and $Z_{2}^{e}$, and having done so, contrast them with their corresponding average values, $\bar{X}_{1}, \bar{X}_{2}, \bar{Y}_{1}, \bar{Y}_{2}, \bar{Z}_{1}$, and $\bar{Z}_{2}$.

Following from this, one can compute the conventional and equity sensitive HDI for each group $k$ $(k=1,2)$ - respectively, $H D I_{k}^{\text {avg }}$ and $H D I_{k}^{e q s}$ - as:

$$
H D I_{k}^{a v g}=\frac{\bar{X}_{k}+\bar{Y}_{k}+\bar{Z}_{k}}{3} \text { and } H D I_{k}^{e q s}=\frac{X_{k}^{e}+Y_{k}^{e}+Z_{k}^{e}}{3}
$$

This is equation (7.15), above.

After this, the EDE index values for the country can be computed, with respect to each of the three achievements, by aggregating across the groups. Doing so takes account of inequality in the distribution of the values of income over all the households in the country: in other words, both inequality between groups and inequality within groups are taken into account in computing the country's EDEPI with respect to income. This is represented by $X^{e}$ where $X^{e} \leq \bar{X}$ and the gap between $X^{e}$ and $\bar{X}$, the average achievement value for the country, depends upon our aversion to inequality (in the extreme case, when there is no aversion to inequality, $X^{e}=\bar{X}$ ). Similarly, we compute $Y^{e}$ (EDEPI for the literacy rate) and $Z^{e}$ (EDEPI for life expectancy). ${ }^{11}$

Following from this, one can compute the conventional and equity sensitive HDI for the country - respectively, $H D I^{\text {avg }}$ and $H D I^{\text {eqs }}$ — as:

$$
H D I^{\text {avg }}=\frac{\bar{X}+\bar{Y}+\bar{Z}}{3} \text { and } H D I^{\text {eqs }}=\frac{X^{e}+Y^{e}+Z^{e}}{3}
$$

This is equation (7.18).

\footnotetext{
${ }^{11}$ As earlier, we use the technique of " $1-\varepsilon$ averaging" as set out in equation (2.16).
} 
Alternatively, one could ignore within group inequality by assuming that every household in a group earns that group's average income. On this assumption, the country's EDE achievement with respect to the income index is represented as $X_{B}^{e}$ where $X_{B}^{e} \leq \bar{X}$ and the gap between $X_{B}^{e}$ and $\bar{X}$, the average achievement value, depends upon our aversion to inequality (in the extreme case, when there is no aversion to inequality, $X_{B}^{e}=\bar{X}$ ). Following from this, the conventional and equity sensitive HDI for the country, respectively, $H D I^{\text {avg }}$ and $H D I_{B}^{\text {eqs }}$, only taking account of between group inequality, are computed as, by equation (7.20):

$$
H D I^{\text {avg }}=\frac{\bar{X}+\bar{Y}+\bar{Z}}{3} \text { and } H D I_{B}^{e q s}=\frac{X_{B}^{e}+Y_{B}^{e}+Z_{B}^{e}}{3}
$$

\subsection{Data and Analysis: the component indices}

The data for the analysis were provided by the household file of the IHDS-2011 which contained information, pertaining to 2011, on over 42,000 households in India. Using these data, the households were divided into the following mutually exclusive groups: Scheduled Tribe (ST), Scheduled Caste (SC), non-Muslim Other Backward Classes (NMOBC), Muslims, non-Muslim Upper Classes (NMUC). These comprised, respectively, $8.2 \%, 21.8 \%, 35.9 \%, 11.4 \%$ and $22.7 \%$ of the sample of households. ${ }^{12}$

The conventional HDI has, as discussed in the previous section, three dimensions: living standards (with GDP as the surrogate), education (with the literacy rate as the surrogate), and health (with life expectancy as the surrogate). Since the analysis reported in this chapter builds up the HDI from the level of the household, taking account of inter- and intra-group inequality, it uses surrogates at the household, rather than at the national, level: household per-capita consumption expenditure (PCE) for living standards and the highest level of education, measured by years of education, of household adult(s) for education. ${ }^{13}$ So as to eliminate extreme values, the maximum and minimum

\footnotetext{
${ }^{12}$ All figures reported in this chapter were obtained after grossing up the sample using the household weights provided in IHDS-2011.

${ }^{13}$ Defined as: 0 (none), 1, 2, 3, 4, 5 (5 $5^{\text {th }}$ standard), 6, 7, 8, 9, 10 (Matric), 11, 12 (Higher Secondary), 13, 14, 15, 16 (Graduate or above).
} 
values of household PCE were taken as the mean values for households in the $95^{\text {th }}$ and $5^{\text {th }}$ quintile of PCE: these were, respectively, ₹68,195 and ₹7,368.

In order to capture more fully the well-being of households, and of the social groups to which they belonged, two further dimensions were added. The first of these was the households' living conditions. The IHDS-2011 reported on the living conditions of the households with respect to a number of items from which this study chose seven, scoring as 1 if the household possessed that item and 0 if it did not: (i) a toilet in their dwelling; (ii) a separate kitchen; (iii) a vent in the cooking place; (iv) a pucca roof; (v) a pucca floor; (vi) electricity; (vii) water supply in the dwelling or its compound. ${ }^{14}$ Thus the maximum and minimum scores score for a household were 7 (it possessed all seven items) and 0 (it possessed none of these items) and the PI for a household, with respect to living conditions, was: [observed score/7] $\times 100$.

Nearly $83 \%$ of households had electricity; the next most commonly possessed housing amenity (73\% of households) was a vent in the cooking area; this was followed by a pucca roof and floor (respectively, $64 \%$ and $59 \%$ of households); the least common amenities were a toilet (53\% of households), a separate kitchen (55\% of households), and water supply within the precincts of the dwelling (51\% of households).

The second additional dimension was social networks. These are important because there is evidence (Bros-Bobbin and Borooah, 2013) that it is difficult in India, if not impossible, to easily access public services unless one 'knows someone' or, in the vernacular, has jaan-pehchaan. ${ }^{15}$ The IHDS-2011 reported on the social networks of each household with respect to a number of indicators designed to measure the range, quality, and the closeness of social contacts. The basic questions were: (i) do you know a person of type $X$ as part of your relatives/caste/community? (ii) If the answer to (i) is no, do you know a person of type $X$ outside your relatives/caste/community? Type $X$ was represented by five professions: (a) doctor; (b) principal/teacher; (c) government officer; (d) elected politician; (e) police inspector.

\footnotetext{
${ }^{14}$ The roof and floor could be: 'kutcha' (grass, mud, thatch, wood, tile, slate for the roof; mud or wood for the floor); or 'pucca' (asbestos, metal, brick, stone, concrete for the roof; brick, stone, cement, tiles for the floor). ${ }^{15}$ Indeed, in the words of a well-known Hindi song (also used to sell Heineken beer): jaan-pehchaan hai, jeena asaan hai (living is easy because I know people).
} 
In this study, a positive answer by a household to question (i) was scored as 2; a positive answer to question (ii) was scored as 1 ; and a score of 0 was assigned to any household that did not know any type $X$ person whether from within its relatives/caste/community or outside. Consequently, the maximum and minimum scores for a household with respect to social networks were 5 (a household knew all five types of persons - doctor, teacher, government officer, elected politician, police inspector — as part of its relatives/caste/community) and 0 (a household did not know any of these five types whether as part of, or outside, its relatives/caste/community: the PI for a household, with respect to social networks was, therefore, [observed score/5] $\times 100$.

The IHDS-2011 showed that the two professions with which households were most acquainted were doctors and teachers: of the sampled households, $20 \%$ and $31 \%$ knew a doctor and a teacher, respectively, as part of their relatives/caste/community. This acquaintance was unevenly distributed between the social groups: $31 \%$ of NMUC households - compared to only $12 \%$ of ST households, $15 \%$ of SC households, $17 \%$ of NMOBC households, and 25\% of Muslim households knew a doctor, while $44 \%$ of NMUC - compared to only $28 \%$ of ST households, $24 \%$ of SC households, 27\% of NMOBC households, and 32\% of Muslim households — knew a teacher/principal.

The least known types were government officers, elected politicians, and police inspectors: only $9 \%, 9 \%$, and $6 \%$, respectively, knew persons of these types as part of their relatives/caste/community. Of households knowing a government officer, $42 \%$ and $28 \%$ belonged to respectively, the NMUC and to the NMOBC; of households knowing an elected politician, $35 \%$ and $29 \%$ belonged to respectively, the NMUC and to the NMOBC; of households knowing a police inspector, $36 \%$ and $30 \%$ belonged to respectively, the NMUC and to the NMOBC. Thus, while not many households could claim to know government officers, elected politicians, or police inspectors as part of their relatives/caste/community, those that could were drawn overwhelmingly from the ranks of the NMUC and the NMOBC.

$<$ Table7.1>

Table 7.1 shows the PI values of each group with respect to the five dimensions of the HDI: living standards; education; life expectancy; living conditions; and social networks. The first number 
in each column is the mean value for each group: this does not adjust for within-group inequality in the distribution of household PI or, in other words, is based on zero aversion to inequality. In terms of the algebra, this number is derived from equation (7.15) with $\varepsilon=0$. The number immediately below this, enclosed in [ ] in Table 7.1, represents the equally distributed equivalent performance index (EDEPI): the mean values reported are adjusted downwards to take account of inter-household inequality within each group. In terms of the algebra, this number is derived from equation (7.15) with $\varepsilon=0.5$, that is with mild inequality aversion.

Table 7.1 shows that, for every dimension, households from the NMUC had the highest, while households from the Scheduled Tribes and the Scheduled Castes had the lowest, PI values. Taking account of inter-household inequality reduced the PI below its mean value. These falls were most marked for the SC and Muslims in terms of education and social networks. The SC have their privileged sub-castes whereby the benefits of reservation in terms of jobs and education are captured by a "creamy layer". ${ }^{16}$ Muslims, too, have their own privileged groups. The Sachar Committee Report (2006) refers to the caste system applying also to Muslims: Muslims who were converts to Islam from the higher castes were ashraf (meaning "noble") and regarded as high-born Muslims, while converts to Islam from the lower castes were ajlaf (meaning "degraded" or "unholy"). As Trivedi et al. (2016) report, there is little social interaction between the two Muslim "castes". The existence of privileged subgroups among deprived groups implies that when allowance is made for intra-group inequality, the values of EDEPI for deprived groups are considerably lower than their corresponding mean values. The SC and Muslims are not only deprived but their deprivation is also compounded by the fact that their attainments are unfairly skewed in favour of a privileged few among them.

\section{Aggregation over Social Groups}

In order to obtain the group achievements in respect of the dimensions - living standards, education, life expectancy, living conditions, and social networks — one needs to aggregate over all the households in each group, using the method of " $1-\varepsilon$ averaging" of equation (7.15), in order to obtain

\footnotetext{
${ }^{16}$ The term "creamy layer" is used here loosely to apply to SC/ST/and Muslims. Strictly speaking, in the Indian legal context, it applies only to the OBC.
} 
the values of performance index of each group (shown in Table 7.1) in respect of that component. If the performance index of group $k(k=1 \ldots)$ with respect to living standards, education, life expectancy, living conditions, and social networks are represented by, respectively, $P I L S^{k}, P I E D^{k}, P I L E^{k}, P I L C^{k}$, and $P I S N^{k}$, then from equation (7.17), the Human Development Index $\left(H D I^{k}\right)$ of each group $k$, over the five dimensions, is defined as:

$$
\begin{aligned}
& H D I 5_{\varepsilon=0}^{k}=\frac{1}{5}\left[P I L S_{\varepsilon=0}^{k}+P I E D_{\varepsilon=0}^{k}+P I L E_{\varepsilon=0}^{k}+P I L C_{\varepsilon=0}^{k}+P I S N 5_{\varepsilon=0}^{k}\right] \text { No inequality aversion }(\varepsilon=0) \\
& H D I 5_{\varepsilon=0.5}^{k}=\frac{1}{5}\left[P I L S_{\varepsilon=0.5}^{k}+P I E D_{\varepsilon=0.5}^{k}+P I L E_{\varepsilon=0.5}^{k}+P I L C_{\varepsilon=0.5}^{k}+P I S N 5_{\varepsilon=0.5}^{k}\right] \text { Mild inequality aversion }(\varepsilon=0.5)
\end{aligned}
$$

These HDI values are shown in Table 7.2. If one interprets a group's HDI value as the percentage fulfilment of its "potential", then the numbers in Table 7.2 show that, in terms of overall human development, households in the NMUC collectively fulfilled $58.9 \%$ of their potential when intra-household inequality was ignored and $53.5 \%$ of their potential when intra-household inequality was taken into account. In contrast, Muslims and NMOBC households fulfilled around $45 \%$ of their potential when intra-household inequality was ignored and 39\% of their potential when intrahousehold inequality was taken into account. Bringing up the rear, ST and SC households fulfilled around $35 \%$ of their potential when intra-household inequality was ignored and around $30 \%$ of their potential when intra-household inequality was taken into account.

\section{$<$ Table 7.2>}

The all-India performance index values for each of the five indicators were shown in Table 7.1, under the column labelled all households, both when intra-household inequality (over all the households in India) was ignored $(\varepsilon=0)$ and when it was taken into account $(\varepsilon=0.5)$. Using these values, equation (7.18) defines the all-India HDI as:

$$
\begin{aligned}
& H D I_{\varepsilon=0}=\frac{1}{5}\left[P I L S_{\varepsilon=0}+P I E D_{\varepsilon=0}+P I L E_{\varepsilon=0}+P I L C_{\varepsilon=0}+P I S N_{\varepsilon=0}\right] \\
& H D I_{\varepsilon=0.5}=\frac{1}{5}\left[P I L S_{\varepsilon=0.5}+P I E D_{\varepsilon=0.5}+P I L E_{\varepsilon=0.5}+P I L C_{\varepsilon=0.5}+P I S N_{\varepsilon=0.5}\right]
\end{aligned}
$$

These all-India values are shown in Table 7.2 as 44.0 (for $\varepsilon=0$ ) and 39.5 (for $\varepsilon=0.5$ ). 


\subsection{Explaining Intra-Household Variation in Performance Indices}

The analysis of the preceding sections highlighted the fact that the performance indices (PI) were unequally distributed between households. The components of the vector $\mathbf{A}_{\mathbf{j}}=\left(A_{1 j}, A_{2 j}, \ldots A_{N_{j}}\right)$ represent the distribution of the PI with respect to indicator $j$ over the $N$ households (indexed, $i=1 \ldots N$ ) in the sample. In the preceding analysis, the sample was divided into five social groups and differences between them, in the average value of their performance indices for each of five indicators, were examined.

These differences, which were shown in Table 7.1, raise three questions. The first and obvious question to ask is whether the numerical differences observed in Table 7.1 were also statistically significant? The second question follows from the observation that households differ in terms of more than just social group membership. For example, different households live in different regions of India; some households reside in rural areas, others are urban residents; households also differ in their principal source of income - some earn their living as agricultural workers, others are salaried employees. The second question is, therefore, whether factors, other than social group, might also have a role in explaining intra-household variation in values of the performance indices? In order to accommodate this possibility, this chapter postulates a relationship between the values of a household's performance index with respect to indicator $j$, represented by $A_{i j}$ for household $i(i=1 \ldots N)$ and its social group, represented by the variable $S_{i}$, its region, ${ }^{17}$ represented by the variable $R_{i}$, its location as an urban/rural resident, represented by the variable $U_{i}$, and its principal source of income ${ }^{18}$ represented by the variable, $V_{i}$. The econometric equations were, therefore, represented by a system of four equations (one for each of the indicators education, consumption, living conditions, and social networks), indexed $j=1 . .4$ :

$$
A_{i j}=\sum_{l=1}^{L} \beta_{j l} X_{i l}+u_{i j}
$$

\footnotetext{
${ }^{17}$ The regions were defined as: North (comprising the states of Jammu \& Kashmir, Delhi, Haryana, Himachal Pradesh, Punjab [including Chandigarh], and Uttarakhand); the Centre (Bihar, Chhattisgarh, Madhya Pradesh, Jharkhand, Rajasthan, and Uttar Pradesh); the East (Assam, Orissa, West Bengal, and the North-Eastern states); the West (Gujarat and Maharashtra); and the South (Andhra Pradesh, Karnataka, Kerala, and Tamil Nadu). ${ }^{18}$ The principal sources of income were: Cultivation \& Allied Agriculture; Agricultural Wage Labour; Nonagricultural Wage Labour; Artisan/Petty Shopkeeper; Organised Business/Salaried/Profession; Pension/Rent/Others.
} 
The $X_{i l}$ in equation (7.23) represent values of $L$ explanatory variables $(l=1 \ldots L)$ for household $i(i=\ldots N)$. In the empirical work reported below, the explanatory variables were $S_{i}$ (social group), $R_{i}$ (region), $U_{\mathrm{i}}$ (urban/rural), and $V_{i}$ (principal source of income). The four equations were estimated as a system using the method of seemingly unrelated regression equations (SURE) due to Zellner (1962, 1963).

The third question relates to the interaction between a household's social group and the other variables. Does the effect of a household's region on its performance index (with respect to a particular indicator) depend upon the social group to which it belongs? If it does, then there is a statistical interaction between a household's region and its social group. Suppose there are two social groups, Hindus and Muslims, and that the variable $M_{i}$ takes the value 1 if a household is Muslim and 0 if it is Hindu. Then interaction between social group and the other variables means that the estimated equation is:

$$
A_{i j}=\sum_{l=1}^{L} \beta_{j l} X_{i l}+\sum_{l=1}^{L} \alpha_{j l}\left(X_{i l} \times M_{i}\right)+u_{i j}
$$

Equation (7.24) shows that the coefficient associated with variable $k$ in the context of a Muslim household (that is, $\left.M_{i}=1\right)$ is $\left(\beta_{j l}+\alpha_{j l}\right)$ while the coefficient associated with the same variable in the context of a Hindu household (that is, $M_{i}=0$ ) is $\beta_{j l}$ : in terms of the estimated coefficients, $\alpha_{j l}$ represents, therefore, the change in variable l's contribution to the performance index (for indicator $j$ ) in moving from a Muslim to a non-Muslim household. Consequently, a test of whether the interaction model is valid is to test the null hypothesis that the coefficients $\alpha_{j l}$ are zero: if this hypothesis is rejected for a number of the $\alpha_{j l}$ - as it was for the SURE coefficients of equation (7.24) — then it would be reasonable to have the social group variables interacting with the other variables.

$<$ Table 7.3>

Table 7.3 shows the values of the predicted performance index (PPI), based on SURE estimates over data for 37,247 households, for each social group, first on an all-India basis and then separately for the five regions. The PPI values were computed using the method of "recycled 
predictions", described in chapter 2, which isolates the effect on the households' PPI of their belonging to different social groups. First, "pretend" that all the 37,247 households are from the SC. Holding the values of the other variables constant (either to their observed sample values, as in this chapter, or to their mean values), predict the values of the PI for each household (for a specific indicator) under this all-SC scenario and denote it $\tilde{p}^{S C}$. Then $\tilde{p}^{S C}$ represents the predicted performance index (PPI) for SC households. Next, "pretend" that all the 37,247 households are Muslim and, again holding the values of the other variables constant, predict the values of the PI for each household (for a specific indicator) under this all-Muslim scenario and denote it $\tilde{p}^{M}$. Then $\tilde{p}^{M}$ represents the predicted performance index (PPI) for Muslim households.

Since the values of the other variables were unchanged between these two hypothetical scenarios, the only difference between them is that, in the first scenario, the SC variable is "switched on" (with the variables pertaining to the other groups "switched off") — while, in the other, the Muslim variable is "switched on" (with the variables pertaining to the other groups "switched off") — for all households. ${ }^{19}$ Consequently, the difference between $\tilde{p}^{S C}$ and $\tilde{p}^{M}$ is entirely due to differences between SC and Muslims. In essence, therefore, in evaluating the effect of two characteristics $X$ and $Y$ on the likelihood of a particular outcome, the method of "recycled predictions" compares two outcomes, first, under an "all have the characteristic $X$ " scenario and, then, under an "all have the characteristic $Y$ " scenario. The values of the other variables remain unchanged between the scenarios. The difference between the two probabilities could then be ascribed to the attribute represented by $X$ and $Y$ (in this case, $\mathrm{SC}$ and Muslim). ${ }^{20}$

The columns of Table 7.3 headed 'PPI' show the PPI values for the five social groups, first on an all-India basis and then for each of the five regions. The all-India values were computed using the method of "recycled predictions", discussed above, by assuming that all the 37,247 households in the estimation sample belonged, successively, to each of the five social groups, with the values of the other variables unchanged. The regional values were also computed using the method of "recycled

\footnotetext{
${ }^{19}$ In operational terms, STATA's margin command will perform these calculations taking into account all interaction effects.

${ }^{20}$ For example, (i) $X$ : all households are SC; $Y$ : all households are Muslim; (ii) $X$ : all households live in the North; $Y$ : all households live in the East.
} 
predictions" but this time assuming that all the 37,247 households in the estimation sample lived in a particular region (say, the North) and, in conjunction with this assumption, belonged, successively, to each of the five social groups, with the values of all the other variables unchanged.

With households from the NMUC as the reference group, the numbers under the column MPI ("marginal performance index") represent the differences between the PPI of a social group and that of the reference group. For example, the all-India PPI for education was 48.2 for the ST and 64.7 for the NMUC yielding an MPI for the ST of 48.2-64.7=-16.5. The associated number under the column headed SE (standard error) shows the standard error associated with the MPI. For the ST, this was 0.79. Dividing the MPI by its SE yields a z-value of 20.9 (not shown in the table) and this implied that the MPI was significantly different from zero. In other words, the education PPI was significantly lower for ST households compared to households from the NMUC.

A similar result emerges for the other social groups with respect to all the indicators. As the other columns of Table 7.3 show, the PPI for households from the NMUC was significantly higher than the PPI for households from the other social groups in respect of: per-capita consumers' expenditure; living conditions; and social networks. In other words, compared to households from the other social groups, households from the NMUC were, on average, significantly more likely to fulfil their potential in respect of education, living standards, living conditions, and social networks. This statement was true not just for India in its entirety but for all its regions considered separately — the North, the Centre, the East, the West, and the South.

There was no significant difference between Muslim and SC households in their PPI for education (respectively, 49.4 and 50.3) but the education PPI for both groups was significantly lower than that for NMOBC households (55.9). In terms of per-capita consumption, however, the PPI for Muslim households (31.4\%) was significantly higher than that for the SC (27.5) but was significantly lower than that for NMOBC households (34.3).

In terms of living standards, however, the PPI of Muslim households (72.9) was significantly higher than that of SC (65.4) and of NMOBC (70.9) households and, in large part, this was explained by the fact that Muslim households were more likely to have a toilet than households from the other groups: $67 \%$ of Muslim households had a toilet compared to $39 \%$ of SC, and $48 \%$ of NMOBC, 
households. The results for social networks mirrored that for living conditions: the PPI of Muslim households (24.0) was significantly higher than that of SC (20.4) and of NMOBC (21.5) households. In large part, this was explained by the fact that Muslim households were more likely to know a doctor or a teacher as a part of relatives/caste/community than households from the other groups: $25 \%$ of Muslim households knew a doctor as a part of relatives/caste/community compared to $15 \%$ of SC, and $17 \%$ of NMOBC, households and 32\% of Muslim households knew a teacher as a part of relatives/caste/community compared to $24 \%$ of SC, and $27 \%$ of NMOBC, households.

\section{$<$ Table 7.4>}

Table 7.3 compared differences between social groups from both an all-India and a regional perspective. Table 7.4, on the other hand, compares differences between regions from both an allIndia and a social group perspective. This table shows that, in terms of three indicators - education, per-capita consumption, and living conditions — the PPI was significantly lower in the Central region and highest in the North, South, and the West. Not only that: households from every social group had a significantly lower PPI in the Central region than they did in other regions. For example, in terms of education, Muslim and SC households had a PPI of 41.8 and 42.7, respectively, in the Central region versus 57.7 and 54.6, respectively in the South. Similarly, in terms of education, households from the non-Muslim upper class had a PPI of 63.2 in the Central region compared to 66.7 in the South.

\subsection{Conclusions}

The novelty of the results presented in this chapter is two-fold. First, by accounting for inequality both within and between social groups, they extend the analysis of mean performance to include equity sensitive human development indices. Second, by including living conditions and social networks, the results go beyond the conventional catalogue of human development indicators - education, life expectancy, and income - to encompass, arguably, a fuller view of well-being.

A persistent, and worrying, feature of the results is that they shows greater intra-group inequality within marginalised and deprived groups — the SC, the ST, and Muslims — than among the "privileged" NMUC. For example, the Gini coefficient for the distribution of the education PI among households in the different subgroups was 0.221 for the NMUC but 0.408 for Muslims, 0.405 
for the SC, and 0.458 for the ST. Similarly, the Gini coefficient for the distribution of the per-capita consumption PI among households in the different subgroups was 0.492 for the NMUC but 0.525 for Muslims, 0.514 for the SC, and 0.596 for the ST.

This raises issues of the existence of a "creamy layer" among the deprived groups — the relatively wealthy members of such groups whose existence only serves to highlight the poverty of those not in this prosperous category. ${ }^{21}$ The existence of such a "creamy layer" implies that when allowance is made for intra-group inequality, the equally distributed index values for deprived groups are considerably lower than their corresponding mean values. Not only are the SC/ST/Muslims deprived, but their poverty is compounded by the fact that such prosperity as might exist among them is captured by a privileged few among their number.

The approach that policy makers in India have taken to overcome the economic and social "backwardness" of the SC and the ST has been two-pronged:

(a) specific measures to combat disparity, including legal safeguards against discrimination in education and employment and the practice of untouchability;

(b) general measures for the economic and social development of all persons, including persons from the SC and ST.

These policies have, undeniably, brought about improvements but, as our analysis shows, there is considerable distance between the development levels of SC, ST, and Muslim households on the one hand, and NMUC households on the other. Like other economically and educationally backward sections from the higher castes, the SC, ST, and Muslims require education and skill development to improve their economic prospects. But, unlike other deprived persons, they face economic and social exclusion and, therefore, require additional protection in the form of antidiscriminatory measures. However, the existence of "exclusion-induced" deprivation means that addressing issues of economic and social exclusion is often more difficult than addressing material poverty. Social and cultural sources of exclusion are rooted in "custom and practice"; they include the practice of untouchability based on caste, and hostility towards Muslims based on history. In this

\footnotetext{
${ }^{21}$ See note 16. The term creamy layer as used here is applied to SC/ST/ and Muslims. Strictly speaking, in the Indian legal context, it applies only to the OBC.
} 
context, efforts to effect the inclusion of groups which are stigmatised faces the special difficulty of combating actions sanctioned by religion, culture, custom, and practice.

A final word about inequality. In the past two decades India has known unprecedented rates of economic growth with a GDP growth rate of $6.3 \%$ in 2017 "disappointing" by earlier standards. As Deaton (2013) points out, inequality is often the consequence of progress: "not everyone gets rich at the same time" (p.1). This can be good if inequality spurs those who have been left behind to catch up with those ahead through say, acquiring education and skills, or migrating from the countryside to towns and cities where the better jobs are located. In this case, inequality is a transient phenomenon accompanying the more durable prize of economic and social progress.

However, inequality can be bad if those who have succeeded attempt to prevent others from doing so. Then inequality becomes entrenched and leads to unrest among those who are left behind and see little hope of catching up. There is danger, however, that this may be the case in India with the rich and poor leading separate lives with no bridges between them. As Rao (2017) has pointed out, "opting out of the public hospitals and government schools that they once used and benefited from, the privileged and middle classes have made their own arrangements to meet their daily needs by setting up private hospitals, private insurance, private schools" (p. xviii). Establishing ladders that enable all citizens of India to climb the wall of economic and social progress is one of the most important challenges facing modern India. 


\section{References}

Anand, S., and Sen, A.K. (1994), Human Development Index: Methodology and Measurement, Human Development Report Office Occasional Paper 12, New York: UNDP.

Anand, S., and Sen, A.K. (1997), Concepts of Human Development and Poverty: A

Multidimensional Perspective, Human Development Report 1997 Papers, New York: UNDP.

Anand, S., and Sen, A.K. (2003), "Gender Inequality in Human Development: Theories and Measurement”, in S. Fukuda-Parr and A.K. Shiv Kumar (eds), Readings in Human Development, Oxford: Oxford University Press.

Atkinson, A.B. (1970), "On the Measurement of Inequality”, Journal of Economic Theory, 2: $244-63$.

Bros-Bobbin, C. and Borooah, V.K. (2013), "Confidence in Public Bodies, and Electoral Participation in India”, European Journal of Development Research 25: 557-583.

Deaton, A. (2013), The Great Escape: health, wealth, and the origins of inequality, Princeton, NJ: Princeton University Press.

Desai, S., Dubey, A., and Vanneman, R. (2015), India Human Development Survey-II, University of Maryland and National Council of Applied Economic Research, New Delhi. Ann Arbor, MI: Inter-university Consortium for Political and Social Research.

Frank, R.H. (1997), “The Frame of Reference as a Public Good”, Economic Journal, 107: $1832-47$.

Frank, R.H. (1999), Luxury Fever: Money and Happiness in an Era of Excess, Princeton and Oxford: Princeton University Press.

Haq, M. (1994), The Birth of the Human Development Index, Human Development Report Office Occasional Paper 1, New York: UNDP.

Layard, R. (2006), Happiness: Lessons from a New Science, London: Penguin Books.

OECD (2011), Compendium of OECD Well-Being Indicators, Paris: Organisation for Economic Co-operation and Development.

Rao, K.S. (2017), Do We Care? India's Health System, Oxford University Press: New Delhi. 
Sachar Committee Report (2006), The Social and Economic Status of the Muslim Community in India, New Delhi: Government of India (Cabinet Secretariat).

Sen, A.K. (1992), Inequality Re-Examined, Oxford: Clarendon Press.

Shariff, A. (1999), India Human Development Report, New Delhi: Oxford University Press. Subramanian, S. (2004), Indicators of Inequality and Poverty, World Institute for Development Economics Research Paper No. 2004/25, Helsinki: WIDER.

Trivedi, P.K., Srinivas, G., Fahimuddin, and Kumar, S. (2016), "Does Untouchability Exist Among Muslims: Evidence from Uttar Pradesh”, Economic and Political Weekly, 51: 32-36.

UNDP (1995), Human Development Report, New York: Oxford University Press.

UNDP (2000), Human Development Report, New York: Oxford University Press.

Zellner, A. (1962), “An Efficient Method of Estimating Seemingly Unrelated Regressions and Tests for Aggregation Bias", Journal of the American Statistical Association 57: 348-368.

Zellner, A. (1963), "Estimators for seemingly unrelated regression equations: Some exact finite same results", Journal of the American Statistical Association 58: 977-992. 
Table 7.1: Household Performance Indices by Social Group

\begin{tabular}{|l|c|c|c|c|c|c|}
\hline & $\begin{array}{c}\text { All } \\
\text { households }\end{array}$ & $\begin{array}{c}\text { Scheduled } \\
\text { Tribes }\end{array}$ & $\begin{array}{c}\text { Scheduled } \\
\text { Castes }\end{array}$ & $\begin{array}{c}\text { OBC } \\
\text { Hindus }\end{array}$ & Muslims & $\begin{array}{c}\text { Non-Muslim } \\
\text { Upper Class }\end{array}$ \\
\hline Per-capita Consumption & 30.3 & 17.4 & 21.1 & 29.8 & 24.7 & 47.1 \\
& {$[26.2]$} & {$[17.3]$} & {$[19.2]$} & {$[25.3]$} & {$[21.6]$} & {$[40.2]$} \\
\hline Education & 49.9 & 37.2 & 41.3 & 49.6 & 42.2 & 66.9 \\
& {$[41.5]$} & {$[26.9]$} & {$[32.2]$} & {$[41.3]$} & {$[32.8]$} & {$[62.0]$} \\
\hline Life Expectancy (years) & 50.1 & 40.8 & 35.0 & 50.5 & 57.3 & 63.7 \\
& {$[50.1]$} & {$[40.8]$} & {$[35.0]$} & {$[50.5]$} & {$[57.3]$} & {$[63.7]$} \\
\hline Living Conditions & 68.1 & 45.5 & 60.5 & 68.1 & 71.5 & 80.7 \\
& {$[66.3]$} & {$[43.2]$} & {$[59.5]$} & {$[64.9]$} & {$[70.5]$} & {$[80.5]$} \\
\hline Social Networks & & & & & & \\
& 21.5 & 18.0 & 17.1 & 19.7 & 21.1 & 30.1 \\
\hline
\end{tabular}

The Performance Index (PI) is defined as [(Observed value - Maximum Value)/(Maximum value - Minimum Value] $\times 100$ The first numbers in each column represent the mean value of the PI for each group. These ignore within-group inequality. The numbers in [ ] take account of within-group inequality: they represent the equally distributed equivalent PI when the inequality aversion parameter, $\varepsilon=0.5$.

The value of the PI for each group represents the average distance between its observed achievement and its potential achievement.

The maximum and minimum values used were: ₹68,195 and ₹7,368 for per-capita consumption; 16 and 0 years of schooling for education; 85 and 25 years for life expectancy; 7 (that is, household possesses all seven items: toilet, kitchen, vent, pucca roof and floor, electricity, and inside water supply) and 0 (household has none of these seven items) for living conditions; 5 (that is, a household knows all five types of persons - doctor, teacher, government officer, elected politician, police inspector - as part of its relatives/caste/community) and 0 (that is, a household does not know any of these types whether from within or outside its relatives/caste/community).

Source: Own calculations from IHDS-2011 
Table 7.2: Human Development Index Values for India, by Social Group*

\begin{tabular}{|l|c|c|c|c|c|c|}
\hline & $\begin{array}{c}\text { Scheduled } \\
\text { Tribes }\end{array}$ & $\begin{array}{c}\text { Scheduled } \\
\text { Castes }\end{array}$ & OBC Hindus & Muslims & $\begin{array}{c}\text { Non- } \\
\text { Muslim } \\
\text { Upper Class }\end{array}$ & All India \\
\hline & & & & & & \\
\hline $\mathrm{HDI}_{\varepsilon=0}$ & 34.8 & 37.0 & 44.8 & 45.1 & 58.9 & 44.0 \\
\hline $\mathrm{HDI}_{\varepsilon=0.5}$ & 27.7 & 31.0 & 38.9 & 39.1 & 53.5 & 39.5 \\
\hline
\end{tabular}

"Life Expectancy, Education, Income, Living Conditions, Social Networks.

Each household's HDI $=(1 / 5) \times \mathrm{LEI}+(1 / 5) \times \mathrm{HEI}+(1 / 5) \times \mathrm{IQI}+(1 / 5) \times \mathrm{LCI}+(1 / 5) \times \mathrm{JPI}$ 
Table 7.3: Predicted Performance Indices for Four Indicators by Social Group and Region

\begin{tabular}{|c|c|c|c|c|c|c|c|c|c|c|c|c|}
\hline & \multicolumn{3}{|c|}{ Education } & \multicolumn{3}{|c|}{ Consumption } & \multicolumn{3}{|c|}{ Living Conditions } & \multicolumn{3}{|c|}{ Social Networks } \\
\hline All-India & PPI & MPI & SE & PPI & MPI & SE & $\mathrm{PPI}$ & MPI & SE & PPI & MPI & SE \\
\hline Scheduled Tribe & 48.2 & -16.5 & 0.79 & 30.7 & -12.9 & 1.6 & 61.2 & -16.3 & 0.62 & 22.0 & -6.2 & 0.65 \\
\hline Scheduled Caste & 50.3 & -14.4 & 0.52 & 27.5 & -16.1 & 1.0 & 65.4 & -12.1 & 0.41 & 20.4 & -7.9 & 0.43 \\
\hline OBC Hindu & 55.9 & -8.8 & 0.44 & 34.3 & -9.3 & 0.9 & 70.9 & -6.6 & 0.35 & 21.5 & -6.7 & 0.36 \\
\hline Muslim & 49.4 & -15.3 & 0.61 & 31.4 & -12.2 & 1.2 & 72.9 & -4.7 & 0.48 & 24.0 & -4.2 & 0.50 \\
\hline Non-Muslim Upper Class [R] & 64.7 & & & 43.6 & & & 77.5 & & & 28.2 & & \\
\hline \multicolumn{13}{|l|}{ North } \\
\hline Scheduled Tribe & 51.8 & -14.0 & 2.73 & 32.9 & -21.9 & 5.4 & 73.9 & -11.0 & 2.15 & 16.4 & -6.6 & 2.25 \\
\hline Scheduled Caste & 54.3 & -11.5 & 0.94 & 35.7 & -19.2 & 1.8 & 79.5 & -5.5 & 0.74 & 19.2 & -3.8 & 0.77 \\
\hline OBC Hindu & 62.2 & -3.7 & 1.08 & 45.0 & -9.8 & 2.1 & 84.9 & -0.1 & 0.85 & 21.5 & -1.5 & 0.89 \\
\hline Muslim & 54.5 & -11.4 & 1.32 & 47.3 & -7.5 & 2.6 & 80.3 & -4.6 & 1.04 & 25.0 & 1.9 & 1.08 \\
\hline Non-Muslim Upper Class & 65.8 & & & 54.9 & & & 85.0 & & & 23.0 & & \\
\hline \multicolumn{13}{|l|}{ Central } \\
\hline Scheduled Tribe & 38.8 & -24.3 & 1.16 & 21.5 & -13.8 & 2.3 & 44.6 & -26.5 & 0.92 & 21.6 & -4.4 & 0.96 \\
\hline Scheduled Caste & 42.7 & -20.4 & 0.97 & 22.0 & -13.3 & 1.9 & 50.1 & -20.9 & 0.77 & 19.5 & -6.4 & 0.80 \\
\hline OBC Hindu & 49.4 & -13.7 & 0.81 & 26.2 & -9.1 & 1.6 & 57.9 & -13.1 & 0.64 & 21.5 & -4.4 & 0.67 \\
\hline Muslim & 41.8 & -21.3 & 1.08 & 24.4 & -10.9 & 2.1 & 67.0 & -4.1 & 0.85 & 21.8 & -4.1 & 0.89 \\
\hline Non-Muslim Upper Class [R] & 63.1 & & & 35.3 & & & 71.1 & & & 26.0 & & \\
\hline \multicolumn{13}{|l|}{ East } \\
\hline Scheduled Tribe & 52.6 & -10.5 & 1.26 & 36.2 & 3.9 & 2.5 & 68.1 & -5.2 & 0.99 & 31.4 & 0.4 & 1.04 \\
\hline Scheduled Caste & 46.7 & -16.4 & 1.14 & 21.8 & -10.5 & 2.2 & 62.7 & -10.6 & 0.90 & 19.3 & -11.7 & 0.94 \\
\hline OBC Hindu & 54.5 & -8.6 & 1.16 & 25.2 & -7.2 & 2.3 & 64.1 & -9.2 & 0.92 & 17.9 & -13.2 & 0.95 \\
\hline Muslim & 44.6 & -18.5 & 1.30 & 18.6 & -13.8 & 2.6 & 64.2 & -9.2 & 1.03 & 24.2 & -6.9 & 1.07 \\
\hline Non-Muslim Upper Class [R] & 63.2 & & & 32.4 & & & 73.3 & & & 31.1 & & \\
\hline \multicolumn{13}{|l|}{ West } \\
\hline Scheduled Tribe & 51.4 & -13.4 & 1.53 & 30.1 & -7.0 & 3.0 & 60.9 & -16.9 & 1.21 & 26.9 & -7.3 & 1.26 \\
\hline Scheduled Caste & 57.2 & -7.6 & 1.35 & 26.6 & -10.4 & 2.7 & 73.0 & -4.8 & 1.07 & 26.2 & -8.1 & 1.11 \\
\hline OBC Hindu & 57.3 & -7.6 & 0.98 & 31.8 & -5.2 & 1.9 & 75.9 & -1.9 & 0.78 & 26.5 & -7.7 & 0.81 \\
\hline Muslim & 49.8 & -15.1 & 1.78 & 25.4 & -11.7 & 3.5 & 73.7 & -4.1 & 1.41 & 24.5 & -9.8 & 1.47 \\
\hline Non-Muslim Upper Class [R] & 64.9 & & & 37.1 & & & 77.8 & & & 34.2 & & \\
\hline \multicolumn{13}{|l|}{ South } \\
\hline Scheduled Tribe & 52.0 & -14.7 & 1.55 & 36.7 & -19.4 & 3.1 & 67.8 & -14.8 & 1.23 & 17.8 & -11.5 & 1.28 \\
\hline Scheduled Caste & 54.6 & -12.1 & 1.04 & 32.2 & -23.9 & 2.0 & 71.1 & -11.4 & 0.82 & 19.5 & -9.8 & 0.85 \\
\hline OBC Hindu & 59.1 & -7.6 & 0.82 & 43.3 & -12.8 & 1.6 & 77.9 & -4.7 & 0.64 & 20.8 & -8.5 & 0.67 \\
\hline Muslim & 57.7 & -9.1 & 1.17 & 40.0 & -16.1 & 2.3 & 79.6 & -2.9 & 0.92 & 25.6 & -3.8 & 0.96 \\
\hline Non-Muslim Upper Class [R] & 66.7 & & & 56.1 & & & 82.5 & & & 29.3 & & \\
\hline
\end{tabular}

[R] denotes reference group

Predicted values computed from SURE estimates on data for 37,247 households.

$\mathrm{PPI}=$ predicted performance Index; MPI=marginal predicted performance index; $\mathrm{SE}=$ standard error.

Source: Own Calculations from IHDS-2011 
Table 7.4: Predicted Performance Indices for Four Indicators by Region and Social Group

\begin{tabular}{|c|c|c|c|c|c|c|c|c|c|c|c|c|}
\hline & \multicolumn{3}{|c|}{ Education } & \multicolumn{3}{|c|}{ Consumption } & \multicolumn{3}{|c|}{ Living Conditions } & \multicolumn{3}{|c|}{ Social Networks } \\
\hline All-India & PPI & MPI & SE & PPI & $\mathrm{MPI}$ & $\mathrm{SE}$ & PPI & $\mathrm{MPI}$ & $\mathrm{SE}$ & PPI & $\mathrm{MPI}$ & SE \\
\hline North & 59.9 & 9.8 & 0.55 & 45.7 & 17.8 & 1.08 & 82.1 & 22.5 & 0.43 & 21.5 & -1.0 & 0.45 \\
\hline Central [R] & 50.1 & & & 27.8 & & & 59.6 & & & 22.5 & & \\
\hline East & 54.2 & 4.1 & 0.51 & 27.4 & -0.5 & 1.00 & 66.5 & 7.0 & 0.40 & 23.8 & 1.3 & 0.42 \\
\hline West & 58.0 & 7.9 & 0.52 & 32.0 & 4.2 & 1.02 & 74.0 & 14.4 & 0.41 & 28.5 & 6.0 & 0.42 \\
\hline South & 59.6 & 9.5 & 0.44 & 44.3 & 16.5 & 0.86 & 76.9 & 17.3 & 0.35 & 23.2 & 0.7 & 0.36 \\
\hline \multicolumn{13}{|c|}{ Scheduled Tribe } \\
\hline North & 51.8 & 13.0 & 2.87 & 32.9 & 11.5 & 5.64 & 73.9 & 29.3 & 2.26 & 16.4 & -5.2 & 2.36 \\
\hline Central $[R]$ & 38.8 & & & 21.5 & & & 44.6 & & & 21.6 & & \\
\hline East & 52.6 & 13.8 & 1.28 & 36.2 & 14.8 & 2.53 & 68.1 & 23.5 & 1.01 & 31.4 & 9.8 & 1.06 \\
\hline West & 51.4 & 12.6 & 1.55 & 30.1 & 8.6 & 3.05 & 60.9 & 16.3 & 1.22 & 26.9 & 5.3 & 1.28 \\
\hline South & 52.0 & 13.2 & 1.61 & 36.7 & 15.2 & 3.16 & 67.8 & 23.2 & 1.27 & 17.8 & -3.8 & 1.32 \\
\hline \multicolumn{13}{|c|}{ Scheduled Caste } \\
\hline North & 54.3 & 11.6 & 1.00 & 35.7 & 13.6 & 1.96 & 79.5 & 29.4 & 0.79 & 19.2 & -0.3 & 0.82 \\
\hline Central [R] & 42.7 & & & 22.0 & & & 50.1 & & & 19.5 & & \\
\hline East & 46.7 & 4.0 & 1.08 & 21.8 & -0.2 & 2.13 & 62.7 & 12.6 & 0.85 & 19.3 & -0.2 & 0.89 \\
\hline West & 57.2 & 14.5 & 1.35 & 26.6 & 4.6 & 2.65 & 73.0 & 22.8 & 1.06 & 26.2 & 6.6 & 1.11 \\
\hline South & 54.6 & 11.9 & 1.04 & 32.2 & 10.2 & 2.04 & 71.1 & 21.0 & 0.82 & 19.5 & 0.0 & 0.85 \\
\hline \multicolumn{13}{|l|}{ OBC Hindu } \\
\hline North & 62.2 & 12.7 & 1.01 & 45.0 & 18.8 & 1.99 & 84.9 & 26.9 & 0.80 & 21.5 & 0.0 & 0.83 \\
\hline Central [R] & 49.4 & & & 26.2 & & & 57.9 & & & 21.5 & & \\
\hline East & 54.5 & 5.1 & 0.98 & 25.2 & -1.0 & 1.92 & 64.1 & 6.2 & 0.77 & 17.9 & -3.6 & 0.80 \\
\hline West & 57.3 & 7.8 & 0.83 & 31.8 & 5.6 & 1.62 & 75.9 & 18.0 & 0.65 & 26.5 & 5.0 & 0.68 \\
\hline South & 59.1 & 9.7 & 0.65 & 43.3 & 17.1 & 1.28 & 77.9 & 19.9 & 0.51 & 20.8 & -0.7 & 0.53 \\
\hline \multicolumn{13}{|l|}{ Muslim } \\
\hline North & 54.5 & 12.7 & 1.44 & 47.3 & 23.0 & 2.83 & 80.3 & 13.4 & 1.13 & 25.0 & 3.1 & 1.18 \\
\hline Central [R] & 41.8 & & & 24.4 & & & 67.0 & & & 21.8 & & \\
\hline East & 44.6 & 2.9 & 1.33 & 18.6 & -5.8 & 2.61 & 64.2 & -2.8 & 1.05 & 24.2 & 2.4 & 1.09 \\
\hline West & 49.8 & 8.0 & 1.82 & 25.4 & 1.1 & 3.58 & 73.7 & 6.7 & 1.44 & 24.5 & 2.6 & 1.50 \\
\hline South & 57.7 & 15.9 & 1.22 & 40.0 & 15.7 & 2.41 & 79.6 & 12.7 & 0.97 & 25.6 & 3.7 & 1.01 \\
\hline \multicolumn{13}{|c|}{ Non-Muslim Upper Class } \\
\hline North & 65.8 & 2.7 & 0.85 & 54.9 & 19.6 & 1.66 & 85.0 & 13.9 & 0.67 & 23.0 & -2.9 & 0.70 \\
\hline Central [R] & 63.1 & & & 35.3 & & & 71.1 & & & 26.0 & & \\
\hline East & 63.2 & 0.1 & 0.99 & 32.4 & -2.9 & 1.94 & 73.3 & 2.3 & 0.78 & 31.1 & 5.1 & 0.81 \\
\hline West & 64.9 & 1.8 & 0.93 & 37.1 & 1.8 & 1.83 & 77.8 & 6.7 & 0.73 & 34.2 & 8.3 & 0.76 \\
\hline South & 66.7 & 3.7 & 0.94 & 56.1 & 20.8 & 1.85 & 82.5 & 11.5 & 0.74 & 29.3 & 3.4 & 0.78 \\
\hline
\end{tabular}

$[\mathrm{R}]$ denotes reference region

Predicted values computed from SURE estimates on data for 37,247 households.

$\mathrm{PPI}=$ predicted performance Index; MPI=marginal predicted performance index; $\mathrm{SE}=$ standard error.

Source: Own Calculations from IHDS-2011 


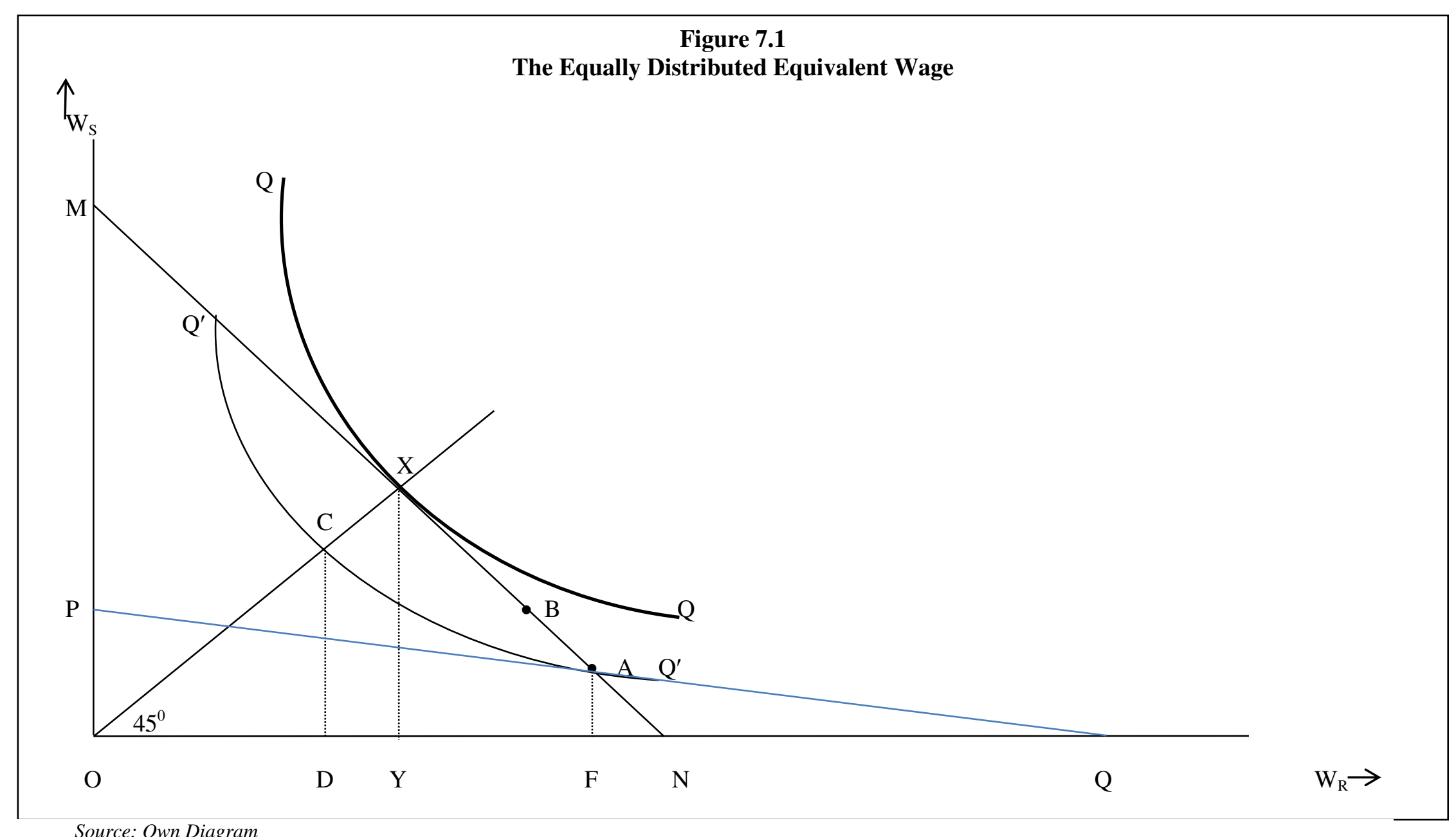


Figure 7.2: The Curvature of the Indifference Curves and the value of $\varepsilon$

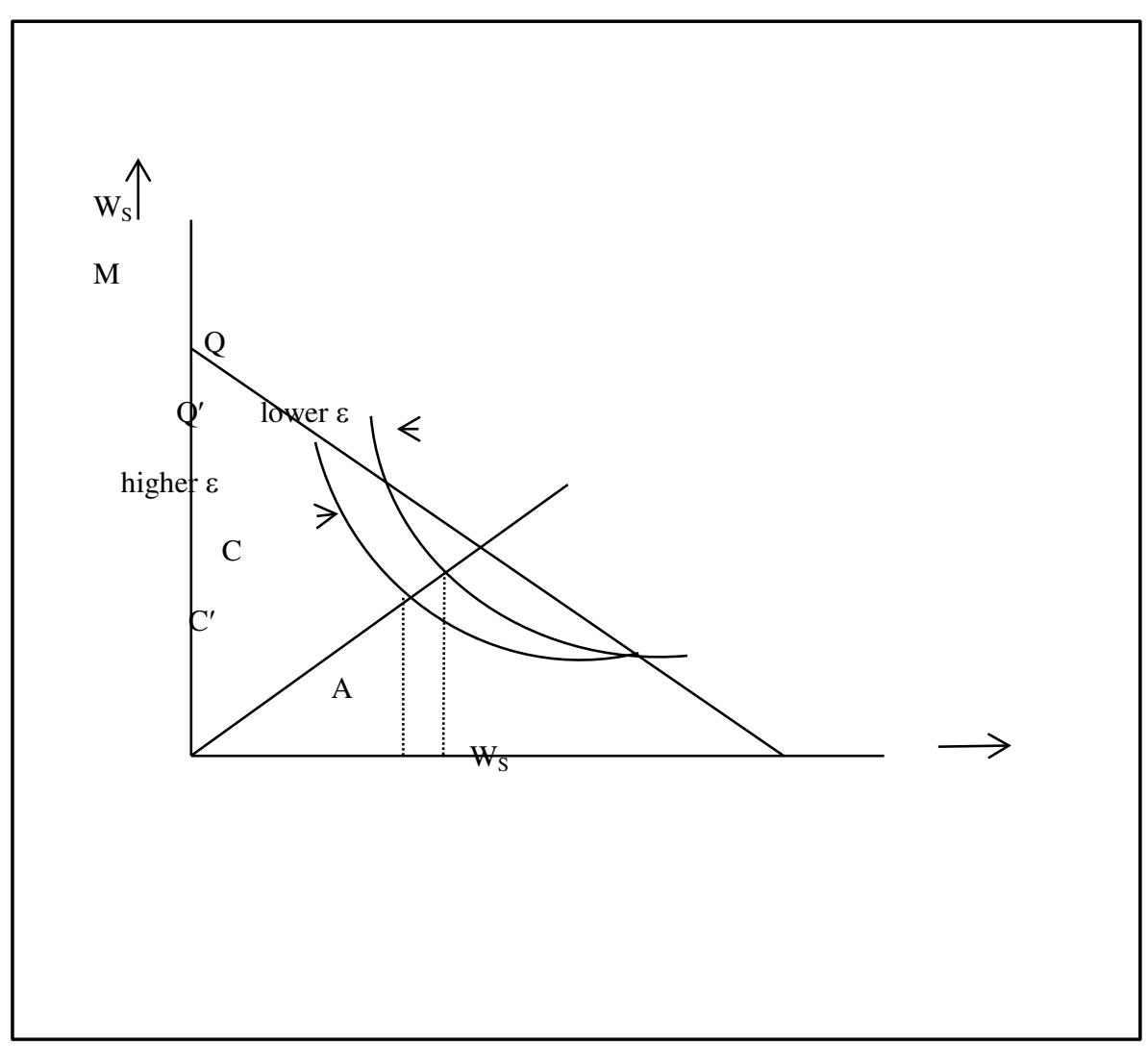

